\title{
Determination of Anthocyanin and Volatile Profile of Wines from Varieties Yiannoudi and Maratheftiko from the Island of Cyprus
}

\author{
Orestis Tsiakkas ${ }^{1}$, Carlos Escott ${ }^{1, *(\mathbb{D}}$, Iris Loira ${ }^{1}\left(\mathbb{D}\right.$, Antonio Morata $^{1, * \mathbb{D}}$, Doris Rauhut ${ }^{2}$ and \\ José Antonio Suárez-Lepe ${ }^{1}$ \\ 1 Chemistry and Food Technology Department, Escuela Técnica Superior de Ingeniería Agronómica, \\ Alimentariay de Biosistemas, Universidad Politécnica de Madrid, Avenida Puerta de Hierro 2, 28040 Madrid, \\ Spain; tsiakkasorestis@gmail.com (O.T.); iris.loira@upm.es (I.L.); joseantonio.suarez.lepe@upm.es (J.A.S.-L.) \\ 2 Department of Microbiology and Biochemistry, Hochschule Geisenheim University, Von-Lade- Straße 1, \\ 65366 Geisenheim, Germany; Doris.Rauhut@hs-gm.de \\ * Correspondence: c.escott@alumnos.upm.es (C.E.); antonio.morata@upm.es (A.M.); \\ Tel.: +34-910671127 (A.M.)
}

Received: 31 October 2019; Accepted: 8 January 2020; Published: 13 January 2020

\begin{abstract}
Anthocyanins and volatile aromas may contribute to the identity of a wine varietal. Various parameters such as terroir (including vineyard altitude), viticultural management, vinification techniques and ageing conditions can influence the physiochemical pathways of the compounds. This work evaluated the anthocyanins and volatile compounds of two monovarietal wines from indigenous varieties, Yiannoudi and Maratheftiko, grown in the island of Cyprus from the vintages 2014, 2015 and 2016. The experimental analysis comprised the determination of anthocyanin's profile (high-performance liquid chromatography-diode array detection chromatography-electrospray ionization tandem mass spectrometry, HPLC-DAD-ESI/MS) and fermentation derived volatiles (gas chromatography-flame ionization detector, GC-FID) and a blind wine testing sensory evaluation. Both the analytical results and the blind wine tasting showed that wines, at their early stage, were easily differentiated by variety, especially in terms of anthocyanins composition, while, in aged wines, the differences among samples were influenced in time by the winemaking procedures and it was not possible to differentiate varieties in such conditions.
\end{abstract}

Keywords: red wine varieties; anthocyanins; Cyprus; Yiannoudi; Maratheftiko

\section{Introduction}

The use of indigenous wine grape varieties allows the production of wines with the particular characteristics of a region. However, the chemical characteristics of these grape varieties are often unknown. This knowledge is important to select the most appropriate winemaking techniques in order to obtain the desired style of wine. It is therefore of great interest to chemically characterise wines from indigenous varieties, considering colour and aroma as the main factors determining the sensory quality.

Regarding anthocyanins in diverse wine grape varieties, the typical concentrations of free anthocyanins in full bodied-young red wines are around $500 \mathrm{mg} / \mathrm{L}$ but, in some cases, can even extend to above $2000 \mathrm{mg} / \mathrm{L}[1,2]$. The types and concentrations of these compounds are influenced by a number of parameters: Soil and climatic conditions, vine cultivations, vine management, grape variety and ripening stage [3].

What is greatly important for anthocyanins is the fact that their concentration can be used for chemotaxonomy of the varieties and, in some cases, even clonal differentiation. It has been proposed 
that there is a relationship between the individual or total concentration of different anthocyanins to present varietal characterization [4-6]. In addition to this, other researches have shown that the amount of acylated anthocyanins is highly variable to the grape variety [7-12].

Alecu et al. [13] investigated the anthocyanin profile of indigenous and international varieties grown in Romania. The anthocyanin profile varied according to the grape variety and was composed of monoglucoside, acetylglucoside and $p$-coumaroylglucoside derivatives [14]. Boss et al. [8] observed that anthocyanins could be used for taxonomy of the varieties tested. Pinot noir has been well-documented as a variety that lacks acylated anthocyanins $[15,16]$. Muscat Rouge had $43 \%$ of malvidin derivatives compared to $80 \%$ of Shiraz and Cabernet Sauvignon, while in in Red Chardonnay and Pink Sultanina, the trihydroxylated anthocyanins were $16.4 \%$ and $25 \%$, respectively [8].

On the contrary, wines originated from varieties that are non Vitis vinifera species contain 3-O-monoglucoside and 3-O-diglucosides. These are pelargonidin-3-5-O-diglucoside (pelargonin), cyanidin-3-5-O-diglucoside (cyanin), delphinidin-3-5-O-diglucoside, peonidin-3-5-O-diglucoside, petunidin-3-5-O-diglucoside and malvidin-3-5-O-diglucoside (malvin) and their corresponding acylated anthocyanins [17-20]. The aforementioned anthocyanins are more stable but they also seem more susceptible to browning reactions under these conditions [19].

In a study conducted by Kokkinofta et al. [21] on Cypriot wines, it was shown that varieties could also be distinguished between them based on their polyphenolic content. The study pointed out an important difference between the content of Cypriot and foreign wines. Vanillic acid was determined in Cypriot wines, as well as an increased concentration of ferulic acid compared with literature data for corresponding foreign wines [21].

Volatile compounds present in wine, on the other hand, shape its sensorial character. The quality of wine is a multifaceted construct, lacking uniformity and with deep complexity. This results for quality are difficult to be determined by just one compound or descriptor [22].

Wine aromas can be associated with the origin of the cultivar as varietal notes, such as terpenes and glycosylated precursors [23], with secondary metabolites from the fermentative process and with tertiary scents from the wine ageing in oak barrels [24]. Wines can be differentiated from one another with the analysis of the such aforementioned fragrances. The combination of all volatiles shapes the character and makes them distinct from one to the other [25]. Some of them originate from the berry itself and other are generated through the fermentation process or even by yeast and bacterial spoilage [26].

It has been observed that varieties Cabernet Sauvignon and Merlot produced wines with the highest concentration of higher alcohols accounting for $88 \%$ and $89 \%$ respectively of the total volatile concentration [27]. Another study showed high values of higher alcohols and ethyl esters in Cabernet Sauvignon wines from China. The alcohol 2-phenylethanol was the compound with the highest concentration in all red wines and the highest being in Cabernet Sauvignon (48.36 mg/L) [28].

In particular, acetate esters are formed by the reaction of acetyl CoA, with higher alcohols formed by the degradation of amino acids or carbohydrates [29]. Thereby, the yeast strain and fermentation conditions play a significant role in the outcome of ester concentrations [27]. From various cultivars, Pinot Noir showed the highest concentration of ethyl esters, with ethyl octanoate and ethyl hexanoate showing major concentrations. On the other hand, isoamyl acetate showed highest concentrations in Tempranillo cultivar. This was in accordance with a research conducted on Tempranillo cultivar [27,30].

In this research, wines from two indigenous varieties, Maratheftiko and Yiannoudi, different wineries and vintages, were assessed using analytical and sensory characteristics. This research aimed to look for a potential chemotaxonomy differentiation between the two varities. 


\section{Materials and Methods}

\subsection{Wine Samples}

Twenty-four commercially available samples from four wineries in the island of Cyprus were selected. These samples comprised two different indigenous varieties Maratheftiko (MAR) and Yiannoudi (YIA), and three vintages (2014, 2015 and 2016). The only exception was the Maratheftiko, which was provided by one of the wineries with a vintage of 201, since vintage 2014 was completely out of stock. All wines selected from vintages 2014 and 2015 were aged for 12 months in barrels. Vintage 2016 had no ageing before analysis.

The wines were kept in a cellar at constant temperature $\left(20^{\circ} \mathrm{C}\right)$ during the experimental analysis. For the purpose of the experimental design, the samples were abbreviated according to the winery's acronym, the variety and the vintage. For example, the sample from Vouni Panayia Yiannoudi 2016 was named VPYIA16. The acronym used for the wineries are: Tsiakkas (TS), KEO (KEO), Argyrides (AR) and Vouni Panayia (VP).

\subsection{Analysis of Volatile Compounds Using GC-FID}

For this analysis, a gas chromatograph coupled with a flame ionization detector (GC-FID) was used. Samples were injected after filtration through $0.45-\mu \mathrm{m}$ cellulose methyl ester membrane filters (Phenomenex, Madrid, Spain). The equipment was an Agilent Technologies 6850 gas chromatograph (Palo Alto, CA, USA). The injection temperature was $250{ }^{\circ} \mathrm{C}$ and the detector temperature was $300{ }^{\circ} \mathrm{C}$. The column used was a DB-624 column $(60 \mathrm{~m} \times 250 \mu \mathrm{m} \times 1.40 \mu \mathrm{m})$. The method temperature ramp was $40{ }^{\circ} \mathrm{C}$ during the first five minutes, then a linear increase of $10{ }^{\circ} \mathrm{C}$ per minute until $250{ }^{\circ} \mathrm{C}$. This temperature was maintained for five minutes. The total runtime of each sample was 40 minutes. The carrier gas used was hydrogen with flow rate in column of $2.2 \mathrm{~L} \mathrm{~min}^{-1}$ and $100 \mu \mathrm{L}$ of internal standard (4-Methyl-2-pentanol, $500 \mathrm{mg} / \mathrm{L}$ ) (Fluka Chemie $\mathrm{GmbH}$, Buchs, Switzerland) was added to $1-\mathrm{mL}$ test samples. Each sample was run by triplicate. This method is a variant of the one recommended by the International Organisation of Vine and Wine (OIV) for the analysis of higher alcohols in wine. The limit of detection was $1 \mathrm{mg} / \mathrm{L}$. The volatile compounds analysed with this technique were previously calibrated with five-point calibration curves $\left(r^{2}\right)$ : Acetaldehyde (0.999), methanol (0.999), ethanol (0.998), 1-propanol (0.999), diacetyl (0.999), ethyl acetate (0.999), 2-butanol (0.999), isobutanol (0.999), acetic acid (0.958), 1-butanol (0.999), acetoin (0.999), 2-methyl-1-butanol (0.999), 3-methyl-1-butanol/isoamyl alcohol (0.999), isobutyl acetate (0.999), ethyl butyrate (0.999), ethyl lactate (0.999), 2,3-butanediol (0.991), isoamyl acetate (0.999), hexanol (0.999), phenylethyl alcohol (0.994) and phenylethyl acetate (0.999) [31].

\subsection{Pigments Characterization}

The nature of the anthocyanins was confirmed using a series 1100 high-performance liquid chromatography (HPLC) system (Hewlett-Packard, Palo Alto, CA, USA) equipped with a diode array detector (DAD) and a quadrupole mass spectrometer series 1100 MSD (Hewlett-Packard, Palo Alto, CA, USA) with an electrospray interface.

Gradients of solvents A (water/formic acid, 95:5 v/v) (Sigma-Aldrich GmbH, Buchs, Switzerland) and B (methanol/ formic acid, 95:5 v/v) (Sigma-Aldrich GmbH, Buchs, Switzerland) were used in a reverse-phase Poroshell $120 \mathrm{C} 18$ column (Phenomenex, Torrance, CA, USA) $(50 \times 4.6 \mathrm{~mm}$; particle size $2.7 \mu \mathrm{m}$ ) as follows: $0-2 \mathrm{~min}, 15 \%$ B (working flow $0.8 \mathrm{~mL} / \mathrm{min}$ ); $2-10 \mathrm{~min}, 15-50 \%$ B linear; $10-12 \mathrm{~min}$, $50 \%$ B; $12-13 \mathrm{~min}, 50-15 \%$ B linear; and 13-15 min, re-equilibration. Detection was performed by scanning in the range of 400-600 nm. Quantification was performed by comparison against an external standard at $525 \mathrm{~nm}$ and expressed as milligram per litre of malvidin-3-glucoside (Extrasynthese, Genay Cedex, France) $\left(r^{2}=0.9999\right)$. Anthocyanins were identified by their retention times and by comparing their UV-visible and mass spectra with data in the literature. Mass spectrometry (MS) was performed in positive scanning mode $(\mathrm{m} / \mathrm{z} 100-1500$, fragmentor voltage $150 \mathrm{~V}$ from 0 to $15 \mathrm{~min})$. 
Twenty microlitre sample of previously filtered $(0.45 \mu \mathrm{m}$ membrane) wines was injected into the HPLC apparatus. The detection limit was $0.1 \mathrm{mg} / \mathrm{L}$. The method was adapted from [32]. Identifications were verified by comparing the mass spectra with previously published molecular ions and mass fragments [33].

\subsection{Wine Tasting Session}

A wine tasting was conducted in Cyprus in collaboration with the Cyprus Sommelier Association and the winemaker's association. Only qualified oenologists and sommeliers were present at the tasting panel. A total of 21 wines were tasted and evaluated by a wine expert panel of 12 people. The age group ranged between 28- and 58-years-old. The tasting was held on a regulated temperature room equipped with proper glassware and spittoons on the table. The purpose of the tasting session was explained to all participants before the tasting. The wines were served in universal Schott Zwiesel glasses, in three rounds of seven wines each, with 10-minute break in between.

The tasting panel was provided with a tasting scoring sheet with three main categories: Colour, aroma and mouthfeel. The different parameters were subdivided further, and each attribute had a scoring range from 1 to 5 [34]. The attributes evaluated were as follows: Colour intensity, hue (tonality), aroma intensity, herbs, flowers, spicy, fruity, reduction, oxidation, body, astringency, alcohol, bitterness, aftertaste, acidity and the overall perception. The attribute designation was adapted to our test from the OIV for wine sensory analysis [35].

\subsection{Statistical Analysis}

Statgraphics v.5 software (Graphics Software Systems, Rockville, MD, USA) was used to calculate means, standard deviation and analysis of variance (ANOVA) and least significant differences (LSD). Significance were set at $p<0.05$ for the ANOVA matrix F value on the results of the sensory analysis. All treatments were evaluated by triplicate. Principal component analysis (PCA) was used in most cases to observe the relationship of the parameters (anthocyanin and volatile composition) that influenced the samples either in negative or in positive mode. No pre-treatment was applied to any variable. This procedure was used mainly to achieve a reduction of dimensionality to permit a primary evaluation of the between-category similarity.

\section{Results and Discussion}

The results shown and discussed herein correspond mostly to the vintages 2014 and 2016. The results obtained for the vintage 2015 did not show trends and the differences were not significant to differentiate the wines by variety or ageing. Therefore, the analysis of pigments, aroma and wine tasting comprised these two vintages previously mentioned.

\subsection{Anthocyanins}

A total of 38 different anthocyanins were identified. The variety Maratheftiko exhibited a total of 31 different anthocyanin pigments and Yiannoudi exhibited a total of 30 different anthocyanins (Table 1). The analysis showed two different unknown anthocyanins at approximately 14-min retention time (RT). Since the anthocyanins had a shoulder at the absorption spectra at ca. $460 \mathrm{~nm}$, this could support the presence of an ethyl linked polymeric compound [36]. Therefore, for the purpose of the analysis, they were classed as polymeric.

Table 1 shows the anthocyanins observed. The retention time, the molecular ion and the fragment ions, and the $\lambda \max$ are given, as well as an indication of the presence of the anthocyanins in any of the varieties studied. In terms of concentrations (data not shown), the highest concentration of total anthocyanins was observed in the sample TSYIA16 with $509.18 \pm 8.18 \mathrm{mg} / \mathrm{L}$ and the lowest in VPMAR13 with concentration $24.44 \pm 2.61 \mathrm{mg} / \mathrm{L}$. However, the sample VPMAR13 was from 2013 vintage. The second lowest concentration observed was KEOMAR14, with a concentration of 48.29 $\pm 1.52 \mathrm{mg} / \mathrm{L}$, which was from the 2014 vintage. In terms of percentage, there was a difference in 
anthocyanins content of $84 \%$ on average from vintages 2013-14 to vintage 2016. The largest difference in anthocyanin content, 95\%, occurred in variety Maratheftiko for the winery VP, while the shortest difference observed, 70\%, was in Yiannoudi for the winery TS. Interestingly, in the vintage 2015, no caffeoyl derivatives were reported on any variety.

Table 1. List of anthocyanins identified in all wine samples.

\begin{tabular}{|c|c|c|c|c|c|c|c|}
\hline & Compound & $\begin{array}{c}\text { RT } \\
(\min )\end{array}$ & $\begin{array}{c}\lambda \max \\
(\mathrm{nm})\end{array}$ & $\begin{array}{l}{[\mathrm{M}]^{+}} \\
(\mathrm{m} / \mathrm{z})\end{array}$ & $\begin{array}{c}\text { Fragment } \\
(\mathrm{m} / \mathrm{z})\end{array}$ & Yiannoudi & Maratheftiko \\
\hline 1 & Malvidin-3-glucoside-(epi)catechin & 4.5 & 530 & 781 & N/A & + & + \\
\hline 2 & Delphinidin-3-glucoside & 6.9 & 524 & 465 & 303 & + & + \\
\hline 3 & Cyanidin-3-glucoside & 8.6 & 515 & 449 & 287 & + & + \\
\hline 4 & Petundin-3-glucoside & 9.8 & 526 & 479 & 317 & + & + \\
\hline 5 & Peondin-3glucoside & 11.2 & 516 & 463 & 301 & + & + \\
\hline 6 & Malvidin-3-glucoside & 12 & 520 & 493 & 331 & + & + \\
\hline 7 & Peondin-3glucoside Pyruvate (vitisin) & 13.4 & 509 & 531 & 369 & + & + \\
\hline 8 & Vitisin B & 12.0 & 523 & 517 & 355 & + & + \\
\hline 9 & Vitisin A & 12.1 & 516 & 561 & 399 & + & + \\
\hline 10 & Unknown & 13.84 & 526 & 609 & 303 & + & + \\
\hline 11 & Unknown & 13.93 & 521 & 479 & 303 & + & - \\
\hline 12 & Deliphinidin-3-(6-Acetylglucoside) & 14 & 533 & 507 & 303 & + & - \\
\hline 13 & Peonidin-3-glucoside Acetaldehyde & 14.8 & 523 & 487 & N/A & + & - \\
\hline 14 & Malvidin-3-glucoside Pyruvate (vitisin A) & 14.3 & 513 & 561 & 399 & + & - \\
\hline 15 & Malvidin-3-(6Acetylglucoside) pyruvate & 14.9 & 518 & 603 & 399 & + & - \\
\hline 16 & Cyanidin-3-(6-acetylglucoside) & 15.8 & 516 & 491 & 287 & + & - \\
\hline 17 & Malvidin-3-glucoside-ethyl-(epi)catechin & 16.1 & 543 & 809 & N/A & + & + \\
\hline 18 & Petunidin-3-(6-acetylglucoside) & 16.2 & 532 & 521 & 317 & + & + \\
\hline 19 & Peonidin-3-(6-acetylglucoside) & 18.7 & 520 & 505 & 301 & - & + \\
\hline 20 & Delphinidin-3-(6-p-coumaroyglucoside) & 19 & 532 & 611 & 303 & - & + \\
\hline 21 & Malvidin-3-(6-acetylglucoside) & 14.9 & 530 & 535 & 331 & + & + \\
\hline 22 & Peonidin-3-(6-caffeoylglucoside) & 19.1 & 524 & 625 & 301 & + & + \\
\hline 23 & Malvidin-3-(6-caffeoylglucoside) & 11.1 & 536 & 655 & 331 & - & + \\
\hline 24 & Cyanidin-3-(6-p-coumaroyglglucoside) & 13.2 & 527 & 595 & 287 & - & + \\
\hline 25 & Malvidin-3-(6-p-coumaroyglucoside)-cis isomer & 15.5 & 537 & 639 & 331 & + & + \\
\hline 26 & Petrundin-3-(6-p-coumaroylglucoside) & 15.8 & 532 & 625 & 317 & + & + \\
\hline 27 & Malvidin-3-glucoside-vinyl-catechin & 16.5 & 503 & 805 & N/A & + & - \\
\hline 28 & Malvidin-3-(6-p-coumaroylglucoside)-ethyl-epicatechin & 16.6 & 540 & 955 & N/A & + & + \\
\hline 29 & Malvidin-3-(6-acetylglucoside)-vinyl-catechin & 16.1 & 508 & 847 & N/A & - & + \\
\hline 30 & Peonidin-3-(6-p-coumaroylglucoside) & 15.8 & 524 & 609 & 301 & + & + \\
\hline 31 & Malvidin-3-(6-p-coumaroylglucoside)-trans isomer & 17.2 & 535 & 639 & 331 & + & + \\
\hline 32 & Malvidin-3-glucoside-4-vinylcatechol & 17.5 & 514 & 625 & 463 & + & - \\
\hline 33 & Malvidin-3-(6-acetylglucoside)-vinyl-epicatechin & 16.5 & 514 & 847 & N/A & + & + \\
\hline 34 & Malvidin-3-glucoside-vinyl-epicatechin & 16.6 & 508 & 805 & N/A & - & + \\
\hline 35 & Malvidin-3-glucoside-4-vinylphenol & 18.6 & 504 & 609 & 447 & + & + \\
\hline 36 & Malvidin-3-glucoside-4-vinylguaicol & 18.6 & 504 & 639 & 477 & + & + \\
\hline 37 & Malvidin-3-(6-acetylglucoside)-4-vinylphenol & 17.2 & 509 & 651 & 447 & - & + \\
\hline 38 & Malvidin-3-glucoside-4-vinylcatechol & 17.5 & 512 & 625 & 463 & - & + \\
\hline
\end{tabular}

Retention time (RT), maximum absorbance wavelength $(\lambda \max )$, molecular ion $[\mathrm{M}]^{+}$, fragment ion (Frag $\left.m / z\right), \mathrm{N} / \mathrm{A}=$ not available, Present (+), Absent (-). 
The compounds were then grouped in seven clusters of anthocyanins in accordance with their molecular structure as follows: Nonacylated monomers, acetyl derivative monomers, vitisins, vinylphenols, coumaroyl derivative monomers, caffeoyl derivative monomers and polymeric pigments (Figure 1). Regardless of the vintage, other authors also found differences in the chemical composition of various red wines that would allow different Cypriot cultivars to be distinguished, including Maratheftiko and Yiannoudi [37].

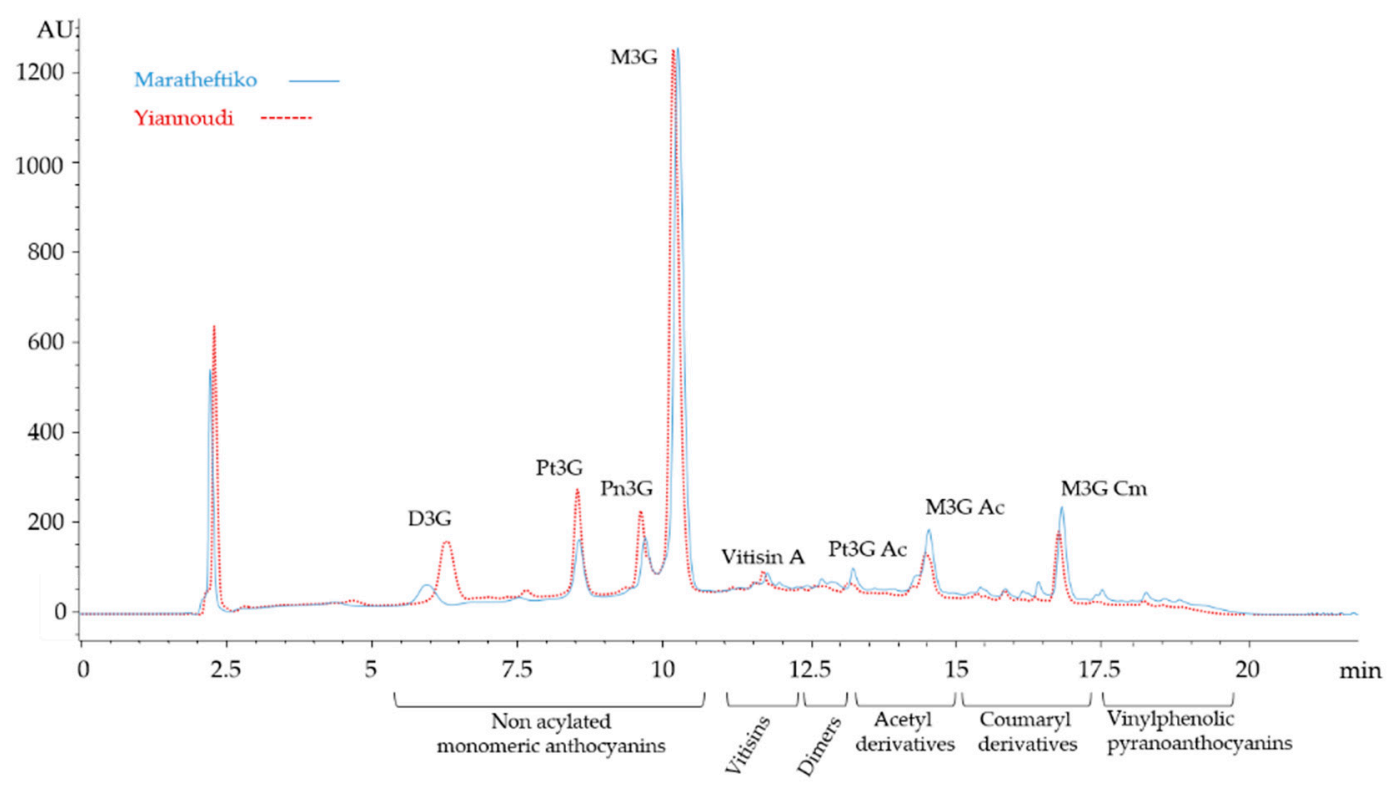

Figure 1. High-performance liquid chromatography (HPLC) of the two indigenous Cypriot varieties, Maratheftiko (continuous blue line) and Yiannoudi (dotted red line). Main anthocyanins are described with abbreviations. D3G-delphinidin-3-glucoside; Pt3G-petunidin-3-glucoside; Pn3G-peonidin-3-glucoside; M3G-malvidin-3-glucoside; Pt3G Ac-petunidin-3-acetylglucoside; M3G Ac-malvidin-3-acetylglucoside and M3G Cm-malvidin-3-coumarylglucoside.

For the statistical analysis PCA plots of 2014 and 2016, vintages were generated in order to visualise whether there were any significant parameters that affects the samples. The PCA of the 2016 vintage (Figure 2A) showed some clustering of the two varieties. The Yiannoudi variety is clustered on the left of the PCA plot and the Maratheftiko variety on the right. Yiannoudi was strongly characterised by having vinylphenols and more vitisins (33.6\% on average), while the Maratheftiko had more concentration of the coumaroyl derivatives (24\%), caffeoyl derivatives $(100 \%)$ and polymeric pigments $(46 \%)$. Figure 1 shows a slightly higher peaks for acylated anthocyanins for the variety Maratheftiko while Yiannoudi has larger concentration of non-acylated anthocyanins. Interestingly, the two varieties were clearly distinguished from one another by pigment content.

The PCA of the 2014 vintage (Figure 2B) shows some interesting results. The samples were clustered under the winery that they were produced at. Unlike the previous results for the 2016 vintage, older vintages were no longer differentiated by variety. In this case, the two varieties showed similar pigment profiles. This is indicated by the circles on each cluster of samples. KEO Coop had KEOYIA14 and KEOMAR14 under the same cluster and Tsiakkas had TSMAR14 and TSYIA14 under the same cluster and VPMAR13 and VPYIA14 under the same cluster. It is worth mentioning that Tsiakkas had a larger amount of non-acylated ( $54 \%$ to $76 \%$ ), polymeric $(27 \%)$, acetyl derivatives $(9 \%$ to $73 \%$ ) and coumaroyl derivatives (56\% to $72 \%$ ), since they are to the right of the positive values of PC 1 and the main difference with the rest of the samples is this. The other two clusters are located to the left, considering the same PC 1 , which had less concentration of pigments. KEO was differentiated by having the highest amount of vitisins (21\% to $65 \%)$ and caffeoyl derivatives $(60 \%)$, while VP, located at 
the bottom left with negative contribution of both components, had the lowest overall concentrations of pigments, $71 \%$ less than the wines with the highest amount of anthocyanins.
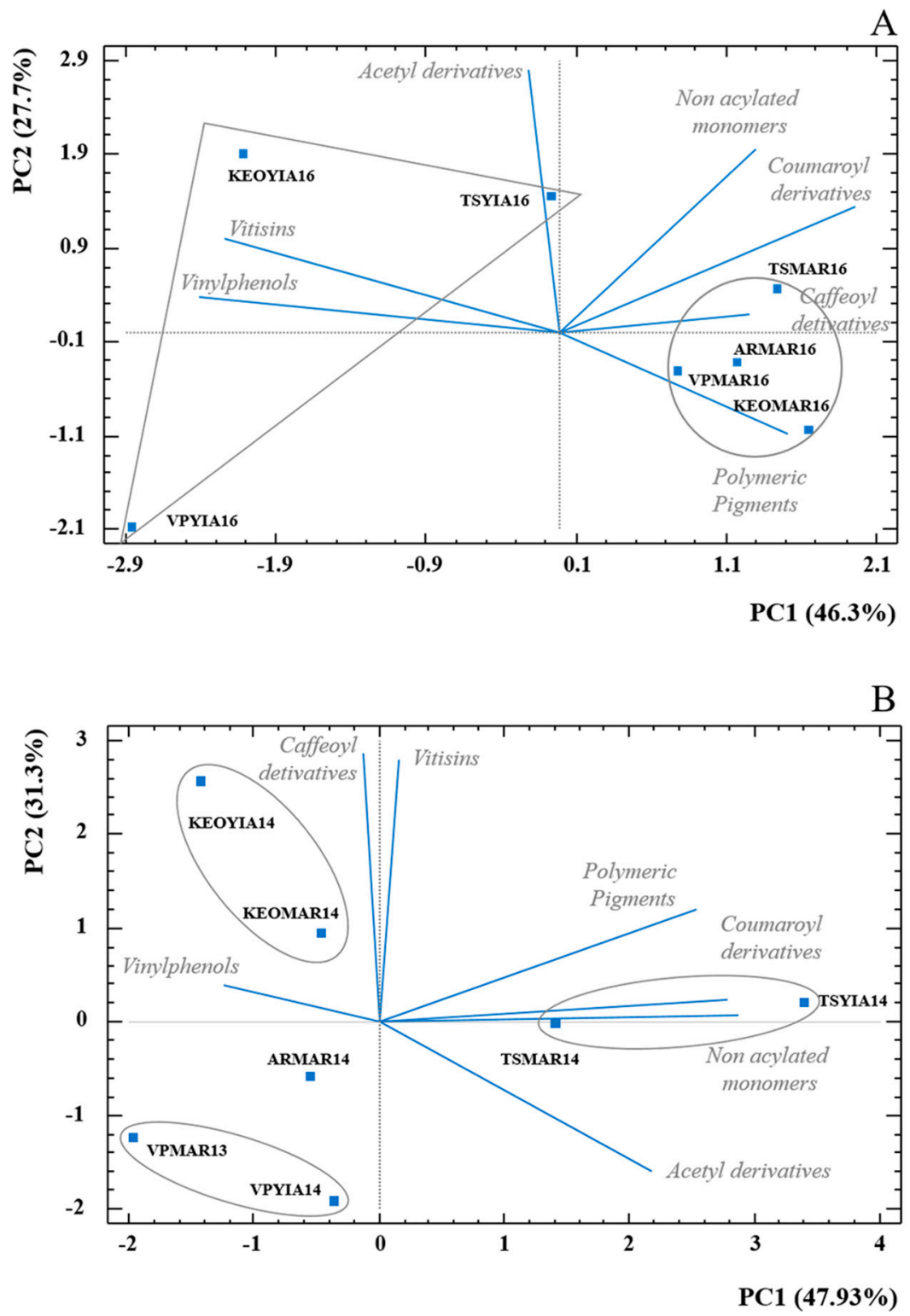

Figure 2. Principal component analysis (PCA) biplot for anthocyanin composition grouped in seven main chemical families for (A) vintage 2016 and (B) vintage 2014. Squares represent average values $(n=3)$ of the seven wine samples. Each wine code is composed by winery initials, variety abbreviation and vintage.

\subsection{Volatile Analysis}

Overall, 24 volatile compounds were quantified (Table 2). Each one of the volatiles was then classed into six family groups: Fruity, oxidation, herbs (green), floral, spicy and other (solvent). This was done to characterise the aromatic profile of each variety with the resemblance they have to those general notes in accordance with the odorant series proposed by Peinado et al. [38]. These aroma groups were later used to run the PCA (Figure 4). The data of the volatile profiles determined by gas chromatography-mass spectrometry (concentration in $\mathrm{mg} / \mathrm{L}$ ) can be found in Table $\mathrm{S} 1$ of the Supplementary Materials. 
Table 2. Aroma descriptor and aroma group of volatile compounds identified with gas chromatographyflame ionization detector (GC-FID).

\begin{tabular}{|c|c|c|c|}
\hline Compound & Fragrance Descriptor & Aroma Group * & Reference \\
\hline Acetaldehyde & Pungent, bruised apple & Fruity & [39] \\
\hline Methanol & $\mathrm{n} / \mathrm{a}$ & $\mathrm{n} / \mathrm{a}$ & \\
\hline Ethanol & $\mathrm{n} / \mathrm{a}$ & $\mathrm{n} / \mathrm{a}$ & \\
\hline 1-propanol & Fresh, Alcohol & Other-Solvent & [25] \\
\hline Diacetyl & Butter & Oxidation & [39] \\
\hline Ethyl acetate & Tropical fruit/honey & Fruity & [40] \\
\hline 2-butanol & Medicinal alcohol & Other-Solvent & [38] \\
\hline Isobutanol & Wine/solvent/bitter & Other-Solvent & [39] \\
\hline Acetic Acid & Acid/Fatty & Oxidation & [25] \\
\hline 1-butanol & Medicinal alcohol & Other-Solvent & [25] \\
\hline Acetoin & Butter/Cream/Butterscotch & Oxidation & [39] \\
\hline 2-methyl-1-butanol & Medicinal Alcohol & Other-Solvent & [38] \\
\hline 3-methyl-1-butanol/Isoamyl Alcohol & Vegetal/pepper & Herbs & [41] \\
\hline Isobutyl acetate & Solvent & Other-Solvent & [25] \\
\hline 4-methyl-2-pentanol & $\mathrm{n} / \mathrm{a}$ & $\mathrm{n} / \mathrm{a}$ & [42] \\
\hline Ethyl butyrate & Fruity/apple & Fruity & [39] \\
\hline Ethyl lactate & Lactic, Raspberry & Fruity & [25] \\
\hline 2,3-butanediol & Butter/creamy & Oxidation & [25] \\
\hline Isoamyl acetate & Banana/Peach/Rose & Fruity & [40] \\
\hline Hexanol & $\begin{array}{c}\text { Green } \\
\text { Floral/herbal/Lemon }\end{array}$ & Herbs & [40] \\
\hline Phenylethyl alcohol & Honey/Rose/Spice & Spicy & [39] \\
\hline Phenylethyl acetate & Floral & Floral & [42] \\
\hline
\end{tabular}

Figure 3 shows a chromatogram of GC-FID analysis for both varieties, Maratheftiko and Yiannoudi. Fermentative volatiles are rather similar for those compounds in higher concentration. The contribution of these volatile compounds as odorant series is detailed with a PCA.

A PCA was run for the volatile compounds in order to depict whether the samples could be categorised under one aromatic profile. The Figure 4A illustrates the 2016 PCA on volatile compounds. As it can be observed, the variety Yiannoudi was more predominant on the spicy, herbs and oxidation notes. The variety Maratheftiko was mainly contributed by the fruity odorant series. TSYIA16 and KEOYIA16 samples showed a relationship with the aforementioned odorant series related to the Yiannoudi variety, with the only exception of VPYIA16 that could be more related to Maratheftiko descriptors (ARMAR16, TSMAR16 and VPMAR16). In addition, the KEOMAR16 was mainly described by the floral series, but was also contributed by the solvent series and total volatile compounds.

The 2014 PCA (Figure 4B) shows that samples from the same winery were grouped together and were mainly differentiated by the fruit factor. This could possibly be explained from the winemaking practices followed at each winery. Nevertheless, this hypothesis should be validated with further information got from future studies including more variables. The samples seem to be affected more by the winery factor and not by the variety factor after ageing, as it has been seen in wines after oxidation in barrels when aromas from wine change and existing aromas could be removed [43,44]. The differences observed between varieties in young wines tend to disappear over time [44]. 


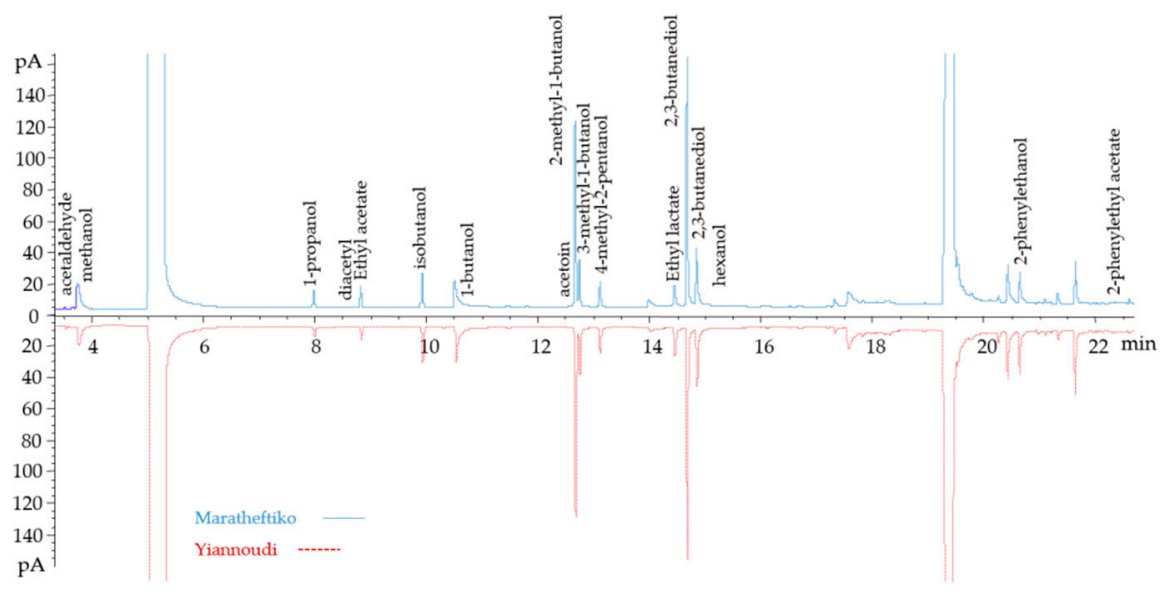

Figure 3. GC-FID chromatogram of the two indigenous Cypriot varieties, Maratheftiko (above) and Yiannoudi (below). Main fermentative volatile compounds are shown.
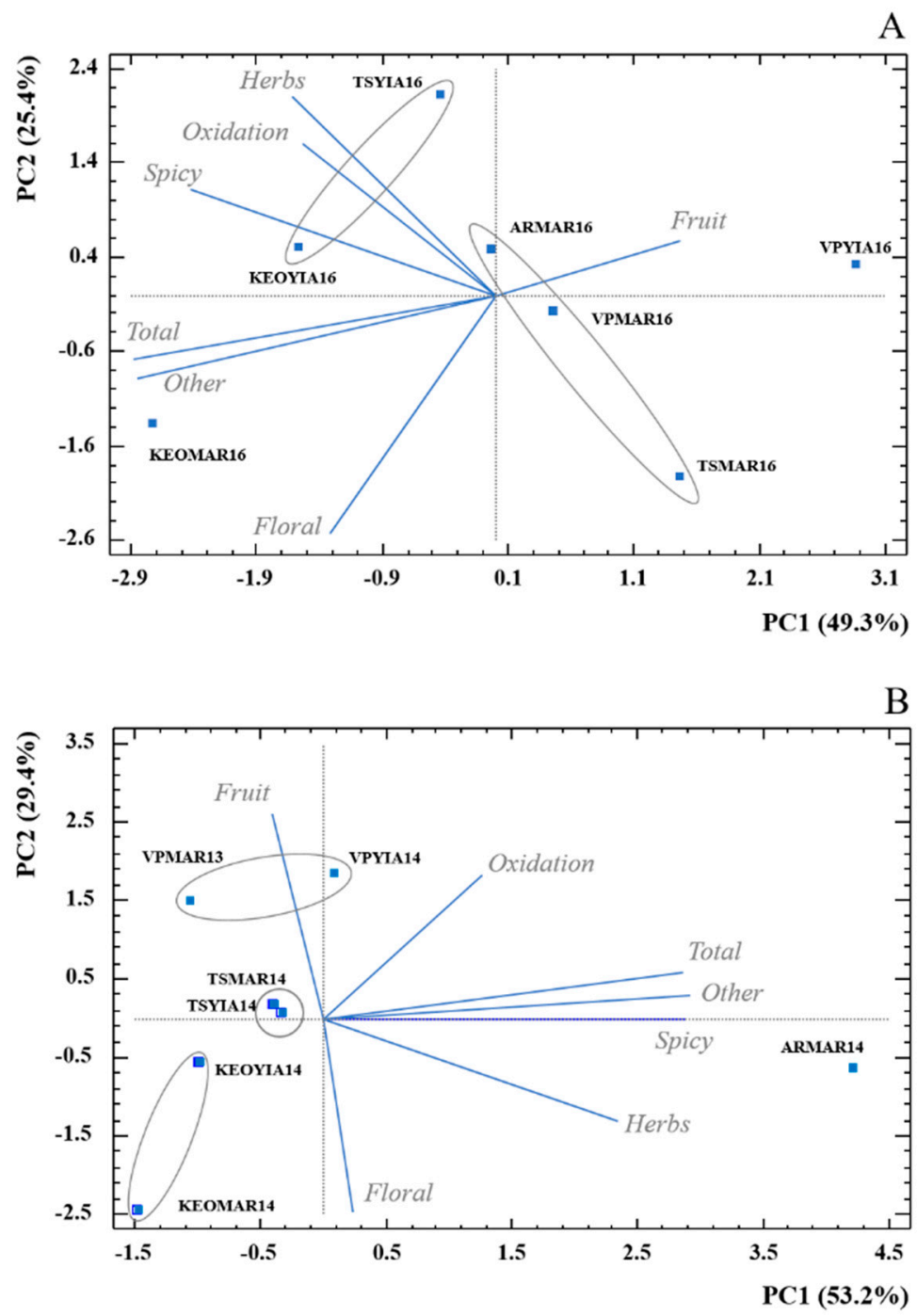

Figure 4. PCA biplot for volatiles composition grouped in seven aroma families according to data from Table 2 for (A) vintage 2016 and (B) vintage 2014. Squares represent average values $(n=3)$ of the seven wine samples. Each wine code is composed by winery initials, variety abbreviation and vintage. 


\subsection{Wine tasting}

All the wines were evaluated through a blind tasting session. The results obtained were used to generate spider charts in order to visualise the differences amongst the varieties. The spider charts are shown in Figure 5A,B. The data of each variety was averaged in order to compare the two varieties amongst them.

A

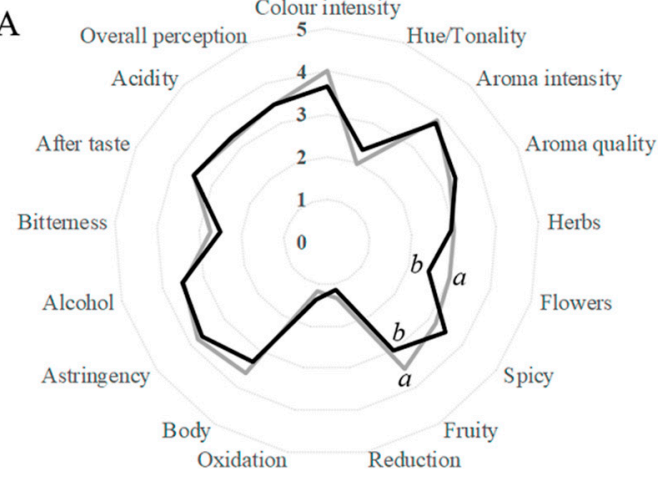

Oxidation Reduction
B Overall perception $\stackrel{\text { Colour intensity }}{5}$ Hue/Tonality

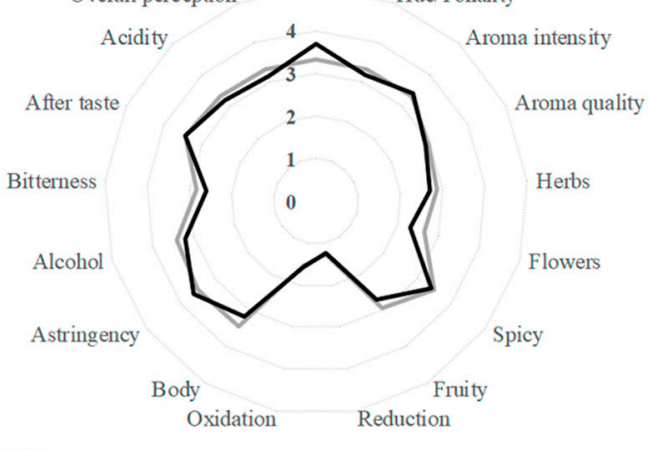

Figure 5. Sensory analysis for wines (A) vintage 2016 and (B) vintage 2014 for the varieties Maratheftiko (MAR) and Yiannoudi (YIA). Each line is the average of $n=4$ wines tasted by 12 panellists. Different letters in the same parameter are significantly different (LSD test, $p<0.05)$. Parameters without letter are not significantly different.

Figure 5A illustrates the comparison of the two varieties for the 2016 vintage. Interestingly, it shows some correlation obtained from the PCA 2016 Aroma Group Analysis (Figure 4A) mentioned earlier in the report. The variety Yiannoudi was found to have more notes of spicy aroma groups using the GC-FID, whereas the Maratheftiko variety was found to have fruitier aromatic groups in the 2016 analysis with a significant difference from the Yiannoudi varieties. The findings of this tasting session are in agreement with the respective vintage session of 2016 using the gas chromatograph.

Further, the variety Maratheftiko showed a higher floral scent (statistical significance between varieties) than the variety Yiannoudi in this tasting session However, this observation can also be somewhat verified from the 2016 Aroma Group Analysis (Figure 4A), since three out of four samples of the Maratheftiko were closely situated together and were influenced from the floral parameter.

The spider chart for the vintage 2014 is indicated below as Figure 5B. As it can be seen, the two varieties were very close to each other and there was no major difference between any of the factors. As already mentioned, the samples after ageing were characterised or grouped according to the winery. Since they exhibited similar factors, the result was expected, and no variety difference can be observed. The variety samples from each winery seem to be affected from the winemaking procedures that cause a similar aromatic and chemical profile to the wines. Thereby at this stage, after the effect of barrel ageing, the wines were more difficult to distinguish from each other.

\section{Conclusions}

The anthocyanin concentration of the two indigenous varieties of Cyprus was shown to be within the normal values and in accordance with previous studies on anthocyanins characterization. The two varieties did not show any significant differences regarding the concentration or the type of the anthocyanins present in the sample. However, when at a young age, the two varieties can be differentiated between, as in accordance with the Anthocyanin PCA of 2016. The factors caffeoyl derivative monomers and polymeric pigments influenced the Maratheftiko variety, whereas the Yiannoudi variety was strongly characterised by the factors of vitisins and vinylphenolics. This is only true for young wines (vintage 2016). When the wines are aged in barrels, it seems that "winemaking" is more predominant, and the wines are grouped by winery and the varieties cannot be distinguished 
(vintage 2014). The results for vintage 2015 appeared to from one stage to the other and no concluding statements were obtained. Further studies, mainly on the characterization of the polymeric fraction, are recommended, as it has been described that the polymerised anthocyanins can be used as a chemotaxonomy in order to distinguish varieties as previously suggested.

The volatile profile of the wines showed similar results to the anthocyanin profile, meaning that the varieties can be differentiated by their aromatic content during their first year. The variety Yiannoudi was more predominant on the spicy, herbs and oxidation notes, as explained by these aromatic compounds. The variety Maratheftiko was mainly explained by the fruit scent. Unfortunately, the varietal factor was lost by the ageing the wines, and thereby the two varieties were indistinguishable between them.

Overall, this study, besides confirming that is possible to distinguish varieties from their anthocyanin and volatile profile, shows that the varietal character can be lost in time, making the wines harder to distinguish between. This brings to question how the usage of influential parameters can, such as yeast, lactic acid bacteria and oak wood aging, help preserve the expression of terroir and variety.

Supplementary Materials: The following are available online at http://www.mdpi.com/2306-5710/6/1/4/s1, Table S1: Concentration of volatile compounds $(\mathrm{mg} / \mathrm{L}$ ) organized by groups of families found in wine samples.

Author Contributions: Conceptualization, O.T.; Methodology, C.E.; Software, I.L.; Validation, A.M. and D.R.; Formal Analysis, O.T.; Investigation, O.T. and C.E.; Resources, J.A.S.-L., A.M. and I.L.; Data Curation, O.T. and C.E.; Writing—Original Draft Preparation, O.T.; Writing-Review \& Editing, C.E. and I.L.; Visualization, A.M.; Supervision, J.A.S.-L., A.M. and D.R.; Project Administration, J.A.S.-L. and A.M. All authors have read and agreed to the published version of the manuscript.

Funding: This research did not receive any specific grant from funding agencies in the public, commercial, or not-for-profit sectors.

Acknowledgments: Especial thanks to the personnel from Universidad Politécnica de Madrid and from Geisenheim University, as well as the Montpellier Sup Agro University. Further on, thanks to the four Cypriot wineries (KEO, Argyrides, Vouni Panayia and Tsiakkas) for the support by providing their samples and Christos Dimitrakopoulos for providing information of the indigenous varieties.

Conflicts of Interest: The authors declare no conflict of interest.

\section{References}

1. He, F.; Liang, N.N.; Mu, L.; Pan, Q.H.; Wang, J.; Reeves, M.J.; Duan, C.Q.; He, F.; Liang, N.N.; Mu, L.; et al. Anthocyanins and their variation in red wines I. Monomeric anthocyanins and their color expression. Molecules 2012, 17, 1571-1601. [CrossRef]

2. He, F.; Liang, N.N.; Mu, L.; Pan, Q.H.; Wang, J.; Reeves, M.J.; Duan, C.Q.; He, F.; Liang, N.N.; Mu, L.; et al. Anthocyanins and their variation in red wines II. Anthocyanin derived pigments and their color evolution. Molecules 2012, 17, 1483-1519. [CrossRef]

3. Viñas, P.; López-Erroz, C.; Marán-Hernández, J.J.; Hernández-Córdoba, M. Determination of phenols in wines by liquid chromatography with photodiode array and fluorescence detection. J. Chromatogr. A 2000, 871, 85-93. [CrossRef]

4. Carreño, J.; Almela, L.; Martánez, A.; Fernández-López, J.A. Chemotaxonomical classification of red table grapes based on anthocyanin profile and external colour. LWT Food Sci. Technol. 1997, 30, 259-265. [CrossRef]

5. Ferrandino, A.; Guidoni, S. Anthocyanins, flavonols and hydroxycinnamates: An attempt to use them to discriminate Vitis vinifera L. cv 'Barbera' clones. Eur. Food Res. Technol. 2010, 230, 417-427. [CrossRef]

6. Pomar, F.; Novo, M.; Masa, A. Varietal differences among the anthocyanin profiles of 50 red table grape cultivars studied by high performance liquid chromatography. J. Chromatogr. A 2005, 1094, 34-41. [CrossRef]

7. Anderson, D.W. Identification of acetic acid as an acylating agent of anthocyanin pigments in grapes. Phytochemistry 1970, 9, 1579-1583. [CrossRef]

8. Boss, P.K.; Davies, C.; Robinson, S.P. Anthocyanin composition and anthocyanin pathway gene expression in grapevine sports differing in berry skin colour. Aust. J. Grape Wine Res. 1996, 2, 163-170. [CrossRef]

9. García-Beneytez, E.; Cabello, F.; Revilla, E. Analysis of grape and wine anthocyanins by HPLC-MS. J. Agric. Food Chem. 2003, 51, 5622-5629. [CrossRef] 
10. Gueffroy, D.E.; Kepner, R.E.; Webb, A.D. Acylated anthocyanin pigments in Vitis vinifera grapes: Identification of malvidin-3-(6-p-coumaroyl) glucoside. Phytochemistry 1971, 10, 813-819. [CrossRef]

11. Mazza, G.; Fukumoto, L.; Delaquis, P.; Girard, B.; Ewert, B. Anthocyanins, phenolics, and color of Cabernet Franc, Merlot, and Pinot Noir wines from British Columbia. J. Agric. Food Chem. 1999, 47, 4009-4017. [CrossRef]

12. Tamura, H.; Hayashi, Y.; Sugisawa, H.; Kondo, T. Structure determination of acylated anthocyanins in Muscat Bailey a grapes by homonuclear Hartmann-Hahn (HOHAHA) spectroscopy and liquid chromatography-mass spectrometry. Phytochem. Anal. 1994, 5, 190-196. [CrossRef]

13. Alecu, A.; Albu, C.; Litescu, S.C.; Eremia, S.A.V.; Radu, G.L. Phenolic and anthocyanin profile of Valea Calugareasca red wines by HPLC-PDA-MS and MALDI-TOF analysis. Food Anal. Methods 2016, 9, 300-310. [CrossRef]

14. Morata, A.; López, C.; Tesfaye, W.; González, C.; Escott, C. Anthocyanins as Natural Pigments in Beverages. In Value-Added Ingredients and Enrichements of Beverages; Grumezescu, A.M., Holban, A.M., Eds.; Woodhead Publishing: London, UK, 2019; pp. 383-428. ISBN 9780128166871.

15. Fong, R.A.; Kepner, R.E.; Webb, A.D. Acetic-acid-acylated anthocyanin pigments in the grape skins of a number of varieties of Vitis Vinifera. Am. J. Enol. Vitic. 1971, 22, 150-155.

16. Rankine, B.C.; Kepner, R.E.; Webb, A.D. Comparison of anthocyan pigments of Vinifera grapes. Am. J. Enol. Vitic. 1958, 9, 105-110.

17. Brown, W.L. The anthocyanin pigment of the Hunt Muscadine grape 1. J. Am. Chem. Soc. 1940, 62, $2808-2810$. [CrossRef]

18. Flamini, R.; Tomasi, D. The anthocyanin content in berries of the hybrid grape cultivars Clinton and Isabella. Vitis 2000, 39, 79-81.

19. Lamikanra, O. Anthocyanins of Vitis rotundifolia hybrid grapes. Food Chem. 1989, 33, 225-237. [CrossRef]

20. Zhao, Q.; Duan, C.Q.; Wang, J.; Zhao, Q.; Duan, C.Q.; Wang, J. Anthocyanins profile of grape berries of Vitis amurensis, its hybrids and their wines. Int. J. Mol. Sci. 2010, 11, 2212-2228. [CrossRef]

21. Kokkinofta, R.; Tzioni, E.; Ioannou-Kakouri, E.; Kanari, P.; Economidou, N.; Damianou, K.; Prokopiou, E.; Krashia, A.; Frantzi, M.; Kakouri, E. Phenolic antioxidants in Cypriot wines as a tool for their varietal discrimination: Preliminary results. J. Chem. Chem. Eng. 2014, 8, 810-818.

22. Hopfer, H.; Nelson, J.; Ebeler, S.; Heymann, H.; Hopfer, H.; Nelson, J.; Ebeler, S.E.; Heymann, H. Correlating wine quality indicators to chemical and sensory measurements. Molecules 2015, 20, 8453-8483. [CrossRef] [PubMed]

23. Ghaste, M.; Narduzzi, L.; Carlin, S.; Vrhovsek, U.; Shulaev, V.; Mattivi, F. Chemical composition of volatile aroma metabolites and their glycosylated precursors that can uniquely differentiate individual grape cultivars. Food Chem. 2015, 188, 309-319. [CrossRef] [PubMed]

24. Dumitriu, G.D.; López De Lerma, N.; Zamfir, C.I.; Cotea, V.V.; Peinado, R.A. Volatile and phenolic composition of red wines subjected to aging in oak cask of different toast degree during two periods of time. LWT Food Sci. Technol. 2017, 86, 643-651. [CrossRef]

25. Jiang, B.; Zhang, Z. Volatile compounds of young wines from Cabernet Sauvignon, Cabernet Gernischet and Chardonnay Varieties grown in the Loess Plateau Region of China. Molecules 2010, 15, 9184-9196. [CrossRef]

26. Torrens, J.; Riu-Aumatell, M.; Lopez-Tamames, E.; Buxaderas, S. Volatile compounds of red and white wines by headspace-solid-phase microextraction using different fibers. J. Chromatogr. Sci. 2004, 42, 310-316. [CrossRef]

27. Vilanova, M.; Genisheva, Z.; Graña, M.; Oliveira, J.M. Determination of odorants in varietal wines from international grape cultivars (Vitis vinifera) grown in NW Spain. S. Afr. J. Enol. Vitic. 2013, 34, $212-222$. [CrossRef]

28. Tao, Y.; Li, H.; Wang, H.; Zhang, L. Volatile compounds of young Cabernet Sauvignon red wine from Changli County (China). J. Food Compos. Anal. 2008, 21, 689-694. [CrossRef]

29. Jackson, R.S. Wine Science: Principles and Applications; Elsevier/Academic Press: Burlington, MA, USA, 2008; ISBN 9780080568744.

30. Ferreira, V.; López, R.; Cacho, J.F. Quantitative determination of the odorants of young red wines from different grape varieties. J. Sci. Food Agric. 2000, 80, 1659-1667. [CrossRef] 
31. Loira, I.; Vejarano, R.; Morata, A.; Ricardo-Da-Silva, J.M.; Laureano, O.; González, M.C.; Suárez-Lepe, J.A. Effect of Saccharomyces strains on the quality of red wines aged on lees. Food Chem. 2013, 139, 1044-1051. [CrossRef]

32. Escott, C.; Vaquero, C.; del Fresno, J.M.; Bañuelos, M.A.; Loira, I.; Han, S.; Bi, Y.; Morata, A.; Suárez-Lepe, J.A. Pulsed light effect in red grape quality and fermentation. Food Bioprocess Technol. 2017, 10, 1540-1547. [CrossRef]

33. Monagas, M.; Núñez, V.; Bartolomé, B.; Gómez-Cordovés, C. Anthocyanin-derived pigments in Graciano, Tempranillo, and Cabernet Sauvignon wines produced in Spain. Am. J. Enol. Vitic. 2003, 54, 163-169.

34. Kulkarni, P.; Loira, I.; Morata, A.; Tesfaye, W.; González, M.C.; Suárez-Lepe, J.A. Use of Non Saccharomyces yeast strains coupled with ultrasound treatments as a novel technique to accelerate aging over lees of red wines and its repercussion in sensorial parameters. LWT Food Sci. Technol. 2015, 64, 1255-1262. [CrossRef]

35. OIV. Review Document on Sensory Analysis of Wine. 2015. Available online: http://www.oiv.int/public/ medias/3307/review-on-sensory-analysis-of-wine.pdf (accessed on 12 July 2018).

36. Morata, A.; Loira, I.; Heras, J.M.; Callejo, M.J.; Tesfaye, W.; González, C.; Suárez-Lepe, J.A. Yeast influence on the formation of stable pigments in red winemaking. Food Chem. 2016, 197, 686-691. [CrossRef]

37. Galanakis, C.M.; Kotanidis, A.; Dianellou, M.; Gekas, V. Phenolic content and antioxidant capacity of Cypriot wines. Czech J. Food Sci. 2015, 33, 126-136. [CrossRef]

38. Peinado, R.A.; Moreno, J.; Bueno, J.E.; Moreno, J.A.; Mauricio, J.C. Comparative study of aromatic compounds in two young white wines subjected to pre-fermentative cryomaceration. Food Chem. 2004, 84, 585-590. [CrossRef]

39. Francis, I.L.; Newton, J.L. Determining wine aroma from compositional data. Aust. J. Grape Wine Res. 2005, 11, 114-126. [CrossRef]

40. Dreyer, E.; Sims, C.; Rouseff, R.; Gray, D.; Sipowicz, M.; Stern, P.M.; Heymann, H.; Nicolau, L. Sensory and compositional characteristics of Blanc Du Bois wine. Am. J. Enol. Vitic. 2013, 64, 118-125. [CrossRef]

41. de-la-Fuente-Blanco, A.; Sáenz-Navajas, M.-P.; Ferreira, V. On the effects of higher alcohols on red wine aroma. Food Chem. 2016, 210, 107-114. [CrossRef]

42. Feng, Y.; Liu, M.; Ouyang, Y.; Zhao, X.; Ju, Y.; Fang, Y. Comparative study of aromatic compounds in fruit wines from raspberry, strawberry, and mulberry in central Shaanxi area. Food Nutr. Res. 2015, 59, 29290. [CrossRef]

43. Kilmartin, P.A. The Oxidation of Red and White Wines and its Impact on Wine Aroma. Chem. N. Z. 2009, 73, 79-83.

44. Ortega-Heras, M.; González-Huerta, C.; Herrera, P.; González-Sanjosé, M.L. Changes in wine volatile compounds of varietal wines during ageing in wood barrels. Anal. Chim. Acta 2004, 513, 341-350. [CrossRef] 